\title{
Odd hydrogen response thresholds for indication of solar proton and electron impact in the mesosphere and stratosphere
}

\author{
Tuomas Häkkilä ${ }^{1}$, Pekka T. Verronen ${ }^{1,2}$, Luis Millán ${ }^{3}$, Monika E. Szelag ${ }^{1}$, Niilo Kalakoski ${ }^{1}$, and Antti Kero ${ }^{2}$ \\ ${ }^{1}$ Space and Earth Observation Centre, Finnish Meteorological Institute, Helsinki, Finland \\ ${ }^{2}$ Sodankylä Geophysical Observatory, University of Oulu, Sodankylä, Finland \\ ${ }^{3}$ Jet Propulsion Laboratory, California Institute of Technology, Pasadena, CA, USA
}

Correspondence: Tuomas Häkkilä (tuomas.hakkila@fmi.fi)

Received: 18 May 2020 - Discussion started: 2 June 2020

Revised: 21 September 2020 - Accepted: 3 November 2020 - Published: 22 December 2020

\begin{abstract}
Understanding the atmospheric forcing from energetic particle precipitation (EPP) is important for climate simulations on decadal time scales. However, presently there are large uncertainties in energy flux measurements of electron precipitation. One approach to narrowing these uncertainties is by analyses of EPP direct atmospheric impacts and their relation to measured EPP fluxes. Here we use observations from the microwave limb sounder (MLS) and Whole Atmosphere Community Climate Model (WACCM) simulations, together with EPP fluxes from the Geostationary Operational Environmental Satellite (GOES) and Polar-orbiting Operational Environmental Satellite (POES) to determine the $\mathrm{OH}$ and $\mathrm{HO}_{2}$ response thresholds to solar proton events (SPEs) and radiation belt electron (RBE) precipitation. Because of their better signal-to-noise ratio and extended altitude range, we utilize MLS $\mathrm{HO}_{2}$ data from an improved offline processing instead of the standard operational product. We consider a range of altitudes in the middle atmosphere and all magnetic latitudes from pole to pole. We find that the nighttime flux limits for day-to-day EPP impact detection using $\mathrm{OH}$ and $\mathrm{HO}_{2}$ are 50-130 protons $\mathrm{cm}^{-2} \mathrm{~s}^{-1} \mathrm{sr}^{-1}(E>10 \mathrm{MeV})$ and $1.0-2.5 \times$ $10^{4}$ electrons $\mathrm{cm}^{-2} \mathrm{~s}^{-1} \mathrm{sr}^{-1}(E=100-300 \mathrm{keV})$. Based on the WACCM simulations, nighttime $\mathrm{OH}$ and $\mathrm{HO}_{2}$ are good EPP indicators in the polar regions and provide best coverage in altitude and latitude. Due to larger background concentrations, daytime detection requires larger EPP fluxes and is possible in the mesosphere only. SPE detection is easier than RBE detection because a wider range of polar latitudes is affected, i.e., the SPE impact is rather uniform poleward of $60^{\circ}$, while the RBE impact is focused at $60^{\circ}$. Altitude-
\end{abstract}

wise, the SPE and RBE detection are possible at $\approx 35-80$ and $\approx 65-75 \mathrm{~km}$, respectively. We also find that the MLS OH observations indicate a clear nighttime response to SPE and $\mathrm{RBE}$ in the mesosphere, similar to the simulations. However, the MLS OH data are too noisy for response detection in the stratosphere below $50 \mathrm{~km}$, and the $\mathrm{HO}_{2}$ measurements are overall too noisy for confident EPP detection on a day-to-day basis.

\section{Introduction}

Solar energetic particle precipitation (EPP) affects the polar atmospheric chemistry directly at the altitude region from the upper stratosphere to the lower thermosphere. Ionization caused by precipitating protons and electrons leads to, for example, the production of odd hydrogen and odd nitrogen from ionic reactions and, subsequently, to the loss of ozone through catalytic reactions (Sinnhuber et al., 2012). There is evidence of EPP-driven variability in winter-springtime ozone (Andersson et al., 2014a; Damiani et al., 2016), which could further connect to decadal variability in regional climate via modulation of polar vortex dynamics and the topdown coupling (e.g., Seppälä et al., 2014).

In atmospheric and climate modeling, EPP forcing can be defined using satellite-based particle flux observations (Matthes et al., 2017, and references therein). Solar wind proton fluxes are continuously measured by detectors aboard the Geostationary Operational Environmental Satellites (GOES) in the geosynchronous orbit (https://www.ngdc.noaa.gov/stp/ satellite/goes/, last access: 17 December 2020). These mea- 
surements provide a good representation of proton forcing because $\mathrm{MeV}$ protons have enough rigidity, i.e., momentum/charge, to penetrate through Earth's magnetic field in polar regions and enter the atmosphere directly from the solar wind. Several studies have shown that the observed atmospheric effects can be well represented in models using the GOES proton observations if the relevant ion-neutral chemistry is considered as well (Jackman et al., 2001; Verronen et al., 2006; Funke et al., 2011; Andersson et al., 2016). For electron precipitation, the situation is different. Electrons have less mass than protons and are captured by Earth's magnetosphere, e.g., in the radiation belts (Baker et al., 2018), from where they are eventually lost either to space or into the atmosphere. Satellite-based observations of electron precipitation fluxes are being made from low-orbiting satellites, but these measurements do not capture full spatiotemporal variability and also suffer from restricted measurement geometry and proton contamination, like in the case of the Medium Energy Proton And Electron Detector (MEPED) and Polarorbiting Operational Environmental Satellite (POES) instruments (Rodger et al., 2010a; van de Kamp et al., 2018). Atmospheric impacts seen in observations seem to indicate a need for a large adjustment of the electron-forcing representation in simulations (Clilverd et al., 2012; Randall et al., 2015). Thus atmospheric observations of EPP impact could help in understanding the uncertainties in the electron flux data and how these flux observations relate to effects in the atmosphere (e.g. Verronen et al., 2011). Thus, EPP detection limits for atmospheric data are valuable information.

Ground-based ionospheric observations provide the most direct measure of EPP atmospheric impact (e.g., Verronen et al., 2015; Heino et al., 2019), but in practice, only satellitebased measurements can offer a global view. Measurement of odd hydrogen species $\left(\mathrm{OH}\right.$ and $\left.\mathrm{HO}_{2}\right)$ are well suited for monitoring EPP impacts due to their relative short chemical lifetime (Verronen et al., 2006; Damiani et al., 2010a). Satellite-based observations of $\mathrm{OH}$ were made continuously in 2004-2009 by the microwave limb sounder (MLS) aboard the Aura satellite (Pickett et al., 2006a, b, 2008). They have since been used to study both solar proton events and electron precipitation (Verronen et al., 2006; Damiani et al., 2010a; Jackman et al., 2011; Andersson et al., 2012; Verronen et al., 2013; Jackman et al., 2014; Andersson et al., 2014b), particularly at $60-80 \mathrm{~km}$ altitudes where the largest EPP events can produce order-of-magnitude increases. Compared to the $\mathrm{OH}$ observations, $\mathrm{MLS} \mathrm{HO}_{2}$ measurements have been made since 2004 and, thus, provide a longer time series than the $\mathrm{OH}$ observations. However, the standard $\mathrm{HO}_{2}$ data from operational processing have a lower signal-to-noise ratio and only cover the lower mesosphere and stratosphere (Pickett et al., 2008; Livesey et al., 2018). Thus, the use of standard $\mathrm{HO}_{2}$ data has been limited to large proton events (Jackman et al., 2011; Zou et al., 2018). An improved offline processing of $\mathrm{HO}_{2}$ data provides better quality (Millán et al., 2015), extending the altitude range to the mesopause and enhancing possibilities for studies of daily EPP impact.

In this paper, we use MLS observations of $\mathrm{OH}$ and $\mathrm{HO}_{2}$ to determine EPP flux thresholds for impact detection in the stratosphere and mesosphere. Looking at different latitude bands and altitudes individually, we first consider large proton events, which have a well-known flux from satellite observations, to develop a method for EPP threshold detection. We then apply the same method to medium-energy electrons for which the satellite-based flux observations are not all inclusive. We compare satellite-data-based thresholds to those from the Whole Atmosphere Community Climate Model (WACCM, version 4) to discuss both limitations of the satellite data and EPP forcing in WACCM. Our results provide the limits of MLS OH and $\mathrm{HO}_{2}$ for EPP detection and usability in EPP studies.

\section{Data and models}

The microwave limb sounder (MLS) measures millimeter and submillimeter thermal emissions from the Earth's limb atmosphere from which temperature, trace gases, and cloud ice are retrieved. Launched in July 2004 into a Sunsynchronous near-polar orbit, the geographic latitude coverage of the measurements is from $82^{\circ} \mathrm{S}$ to $82^{\circ} \mathrm{N}$ on each orbit, and measurements are made during both day and night conditions. The instrument is described in detail by Waters et al. (2006). A detailed description of MLS version 4 data products and quality is given by Livesey et al. (2018). The MLS target species in the stratosphere and mesosphere include $\mathrm{OH}$ and $\mathrm{HO}_{2}$.

For the version $4 \mathrm{OH}$ data used in our study, the recommended pressure range of observations is $32-0.0032 \mathrm{hPa}$ (approx. altitudes $25-95 \mathrm{~km}$ ). At levels with $p>0.01 \mathrm{hPa}$, the vertical resolution of observations is $2.5 \mathrm{~km}$. Version 2.2 data have been validated with balloon-borne remote sensing instruments and with ground-based column measurements (Pickett et al., 2008; Wang et al., 2008). Instead of the standard $\mathrm{HO}_{2}$ data, we use data from the offline processing described in detail and validated against other observations by Millán et al. (2015). This algorithm retrieves daily zonal means of $\mathrm{HO}_{2}$ over an extended vertical range by first averaging the radiances in $10^{\circ}$ bins, resulting in a better signalto-noise ratio and an extended altitude range compared to the standard $\mathrm{HO}_{2}$ data. The recommended pressure range for the offline $\mathrm{HO}_{2}$ data is $10-0.0032 \mathrm{hPa}(\approx 35-90 \mathrm{~km})$, and the vertical resolution is about $4 \mathrm{~km}$ between 10 and $0.1 \mathrm{hPa}$, $8 \mathrm{~km}$ at $0.02 \mathrm{hPa}$, and around $14 \mathrm{~km}$ for lower pressures. Daytime and nighttime data are provided separately, using measurement tangent point solar zenith angle limits $<90$ and $>100^{\circ}$, respectively.

The Whole Atmosphere Community Climate Model (WACCM) is a chemistry-climate model that extends from the surface to about $5.9 \times 10^{-6} \mathrm{hPa}(\approx 140 \mathrm{~km})$, with a hori- 
zontal resolution of $1.9^{\circ}$ latitude by $2.5^{\circ}$ longitude. WACCM physics and atmospheric responses to solar and geomagnetic forcing variations are described by Marsh et al. (2007). Details about WACCM version 4 coupled simulations and an overview of the model climate can be found in Marsh et al. (2013). Here, we utilize WACCM-D, a variant of WACCM version 4 in which standard parameterization of EPP-driven odd hydrogen and odd nitrogen production is replaced by a set of D-region ion chemistry reactions (Verronen et al., 2016) and which better reproduces the observed $\mathrm{OH}$ response during EPP (Andersson et al., 2016). We used WACCM-D in the specified dynamics scenario (SD-WACCM-D) forced with meteorological fields (temperature, winds, and surface pressure) from the ModernEra Retrospective analysis for Research and Applications (MERRA; Rienecker et al., 2011). The daily atmospheric ionization rates due to $1-300 \mathrm{MeV}$ solar protons are calculated based on flux data available from the National Oceanic and Atmospheric Administration (NOAA) Space Environment Center (https://www.ngdc.noaa.gov/stp/satellite/goes/ dataaccess.html, last access: 17 December 2020) and the methodology discussed in Jackman et al. (2009). These are applied at geomagnetic latitudes $>60^{\circ}$ in both hemispheres. The daily zonal mean ionization rates at geomagnetic latitudes $40-72^{\circ}$ from precipitating $30-1000 \mathrm{keV}$ electrons are taken from the APEEP (Ap-driven energetic electron precipitation) proxy model, which is recommended for the Coupled Model Intercomparison Project (CMIP; van de Kamp et al., 2016; Matthes et al., 2017). We carried out a simulation for a period between 2000-2012, which covers the whole period of MLS OH observations. WACCM-D output, including $\mathrm{OH}$ and $\mathrm{HO}_{2}$, was saved at MLS measurement times and locations to ensure a one-to-one match between the model and the measurements in the analysis.

EPP forcing patterns follow the geomagnetic latitudes rather than the geographic ones, and the odd hydrogen response is expected to show similar patterns due to its short chemical lifetime (e.g., Andersson et al., 2018). Thus, we use a modified version of the $\mathrm{HO}_{2}$ offline algorithm in which the radiances were averaged using geomagnetic latitudes instead of geographic latitudes (for a definition of altitudeadjusted corrected geomagnetic coordinates, see, e.g., Shepherd, 2014). These geomagnetic latitudes are shown in Fig. 1. Before the analysis, the MLS OH and WACCM-D data were preprocessed the same way as it was done for $\mathrm{HO}_{2}$. The data were divided into daily daytime and nighttime sets, using the same solar zenith angle limits, and averaged zonally after sorting observations into $10^{\circ}$ geomagnetic latitude bins, running from $-85^{\circ}$ through to $+85^{\circ}$. Through this paper, these bins are referred to by their central latitude, i.e., the latitude $40^{\circ}$ refers to the zonal average from geomagnetic latitudes $35-45^{\circ}$. It should be noted that, due to separating the data both by latitude and by day/night conditions, there is sometimes little data available at the highest latitudes. For example, sometimes there is no nighttime data in June for latitude $80^{\circ}$. The daily averages of existing data points at the high geomagnetic latitude bins may also be skewed towards lower geographic latitudes. However, this should not affect our comparisons because WACCM-D was sampled at the MLS times and locations and binned in the same manner.

In the analysis, we use the pressure level grid from the MLS measurements, as sections of the MLS $\mathrm{HO}_{2}$ and $\mathrm{OH}$ pressure grids are the same. Hence, the overlapping sections of $\mathrm{MLS}^{\mathrm{HO}} 2$ and $\mathrm{OH}$ values were selected, whereas the least squares interpolation method recommended by Livesey et al. (2018) was used to convert WACCM-D data onto the MLS grid. The same pressure grid allows for direct comparisons between the data sets. The MLS $\mathrm{HO}_{2}$ offline data are provided in both mixing ratios (parts per million by volume ppmv) and concentrations (molec. $\mathrm{cm}^{-3}$ ). Thus, daily total density profiles can be calculated by dividing $\mathrm{HO}_{2}$ concentrations by $\mathrm{HO}_{2}$ mixing ratios. To ensure consistency between the data sets, MLS OH and WACCM-D data were converted from mixing ratios to concentrations using the same total densities from MLS $\mathrm{HO}_{2}$. For the general comparisons, the MLS $\mathrm{HO}_{2}$ averaging kernels were applied to the WACCM-D $\mathrm{HO}_{2}$ fields. As most of the averaging kernels are fairly similar, only the daytime and nighttime kernels corresponding to magnetic equator were used and applied to all latitude bins. MLS averaging kernels were not used on WACCM-D OH data because the effect was expected to be small. In the threshold detection, the MLS averaging kernels were not applied on WACCM-D $\mathrm{HO}_{x}$ data.

In order to show the connection between EPP and odd hydrogen changes, we use proton flux measurements from the Geostationary Operational Environmental Satellite (GOES11; https://www.ngdc.noaa.gov/stp/satellite/goes/, last access: 17 December 2020) as a measure of proton precipitation over the polar caps. Daily average fluxes of protons with energies greater than $10 \mathrm{MeV}$ are used as an indicator because those directly affect atmospheric altitudes below about $90 \mathrm{~km}$ (for the relation between EPP energies and penetration altitudes, see Turunen et al., 2009, Fig. 3). The measurements from the other GOES channels responding to higher proton energies correlate well with the $>10 \mathrm{MeV}$ channel (not shown), so we would not expect significant changes in our results if other proton energy channels were used. As a measure of electron precipitation, we use flux observations from the Medium Electron Proton and Electron Detector (MEPED) aboard the Polar Orbiting Environmental Satellite (POES; Evans and Greer, 2004). Daily average electron fluxes from an energy range between 100 and $300 \mathrm{keV}$, and from the $50^{\circ}$ magnetic latitude bin, are used as indicator of the radiation belt electron precipitation (RBE) affecting mesospheric altitudes. While the magnitude of RBE forcing will depend on latitude more than for the proton forcing, the $50^{\circ}$ latitude bin was selected because of its most pronounced atmospheric $\mathrm{HO}_{x}$ impact (e.g., Verronen et al., 2011). The assumption here is that the RBE forcing will vary similarly with magnetic activity across affected latitudes, although the magni- 


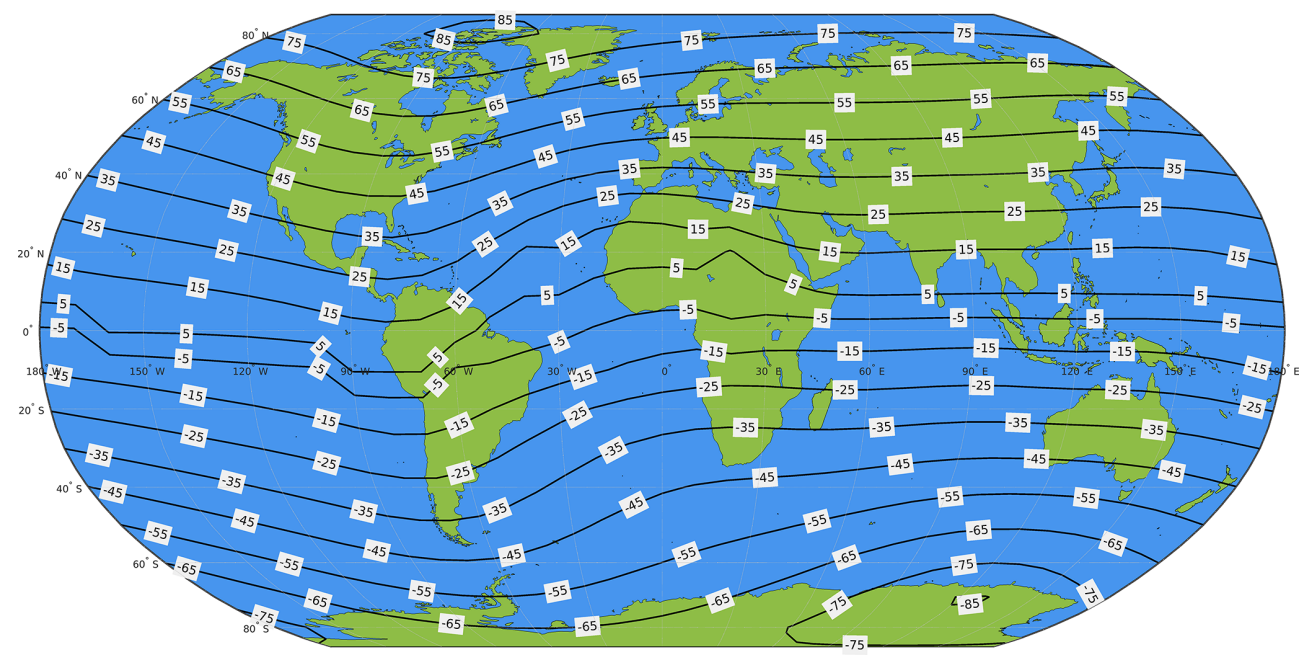

Figure 1. Geomagnetic latitude bin limits used in the analysis.

tude can differ. The electron flux data are exclusively from the zero-degree telescope and have been preprocessed to remove known quality issues (for a description, see Verronen et al., 2011, and references therein), e.g., data suffering from proton contamination have been excluded using the methods described by Rodger et al. (2010a).

\section{Methods}

First, we present an overall comparison between WACCM-D and MLS odd hydrogen data. We use monthly average concentrations to identify the main similarities and differences between the data sets, focusing on the shape, strength, and location of concentration peaks. These comparisons provide us with information on the overall representation of odd hydrogen in WACCM-D, which can help us to understand the differences in EPP detection thresholds.

Starting from the approach of Verronen et al. (2011), we use daily average data in EPP detection. However, Verronen et al. (2011) studied only four selected RBE events, and although they demonstrated the correlation between EPP and $\mathrm{OH}$, they did not use $\mathrm{HO}_{2}$ data or pursue the detection limits. Before determining threshold values for the SPE and RBE detection, daily climatologies of $\mathrm{OH}$ and $\mathrm{HO}_{2}$ concentrations were removed from the odd hydrogen data. Climatological values were calculated for each day of the year by first calculating the daily average $\mathrm{OH}$ and $\mathrm{HO}_{2}$ night and day concentrations of available data at each grid point, separately, for WACCM-D and MLS. A $9 \mathrm{~d}$ moving average was then calculated to smooth the time series and produce the final climatologies. After the climatology is removed, the background concentrations do not display seasonal variability, which makes it possible to combine EPP event periods from different seasons for the threshold detection. Examples of this deseasonalizing effect can be seen in Fig. 2.
It should be noted that after the climatology is removed, the $\mathrm{HO}_{x}$ concentrations still have variability from sources other than EPP, and these are included in the data in our analysis. For example, sudden stratospheric warmings (SSWs) contribute to the year-to-year $\mathrm{OH}$ variability in the Northern Hemisphere (NH) middle atmosphere (Damiani et al., 2010b). As our aim is to determine the general threshold values for SPE and RBE detection, we do not separate SSWs years in any particular manner. However, we consider Southern Hemisphere ( $\mathrm{SH}$ ) and $\mathrm{NH}$ separately, and only the $\mathrm{NH}$ is regularly affected by SSWs.

For the SPE threshold determination, we selected data from all months during which the daily proton flux indicates an event, i.e., it exceeds the limit of 10 protons $\mathrm{cm}^{-2} \mathrm{~s}^{-1} \mathrm{sr}^{-1}$ (see Fig. 3a). All months used in the analysis are listed in Table 1. Using data from the selected months, we applied a fitting method previously used by Verronen et al. (2011). First, we plotted the SPE flux values against the climatology-free odd hydrogen concentrations (i.e., anomalies). Then, a firstdegree polynomial was fitted to the $\mathrm{HO}_{x}$ anomalies and the square root of the SPE fluxes. A limit for a significant SPEdriven enhancement in odd hydrogen concentration was calculated by adding the standard deviation of the concentrations to the median concentration. Since the concentrations are deseasonalized, the median is expected to be close to zero. The addition of the standard deviation suggests that a concentration anomaly of 1 standard deviation from the climatology is significant and should be detected. We then find the SPE indicator value at the intersection of the limit and the linear fit; this is the detected SPE threshold flux value. Examples of the SPE threshold determination are shown in Fig. 4a. This process is applied for each latitude bin and at each pressure level separately. To identify those thresholds that are reasonable, they are filtered using correlations between the square root of the SPE fluxes and odd hydrogen concentra- 

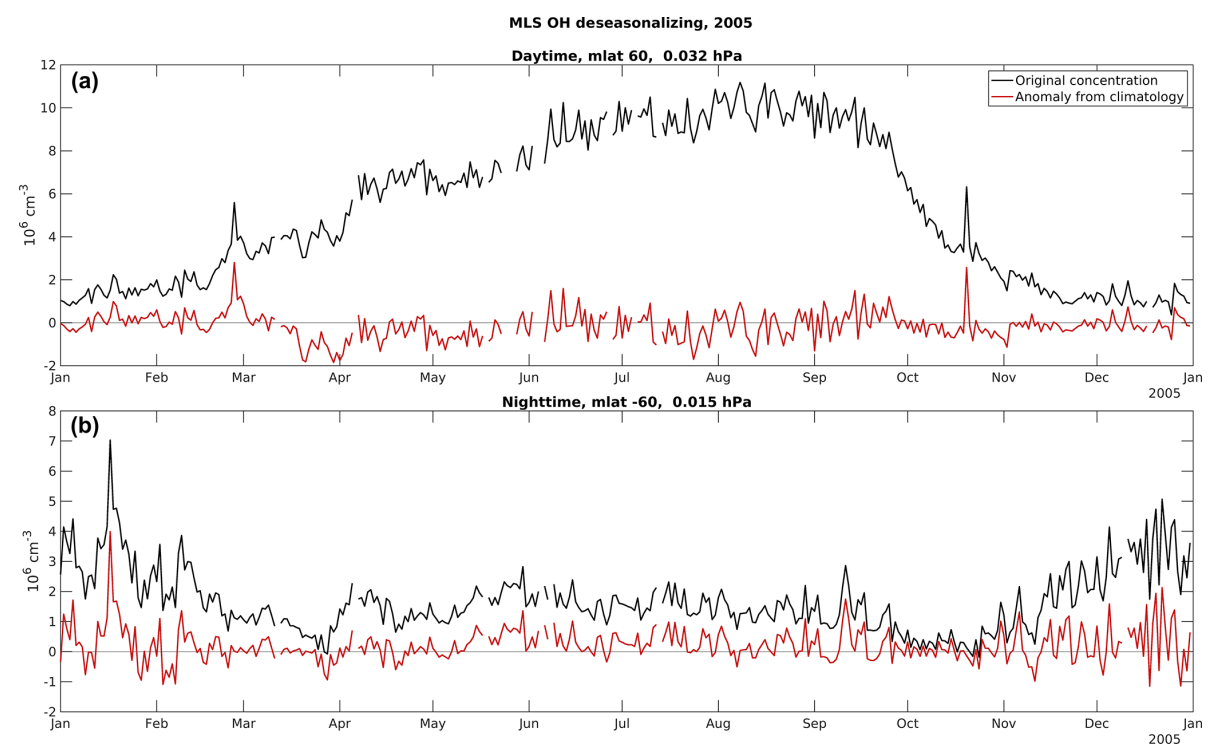

Figure 2. Daily MLS OH concentrations (in black) and the deseasonalized anomalies from the climatology (red) in 2005. Daytime (a) on magnetic latitude $60^{\circ} \mathrm{N}$ at $0.032 \mathrm{hPa}$ and nighttime (b) on magnetic latitude $60^{\circ} \mathrm{S}$ at $0.015 \mathrm{hPa}$.

tions. All thresholds with corresponding correlation coefficient $\geq 0.35$ are accepted as reasonable, and the rest are discarded. This filtering effectively removes threshold values at lower latitudes where SPE impact is not expected.

The RBE threshold values are determined using the same method but with different RBE flux and correlation limits. RBE months were found using an RBE flux limit of $1.5 \times 10^{4}$ electrons $\mathrm{cm}^{-2} \mathrm{~s}^{-1} \mathrm{sr}^{-1}$ (see Fig. 3b), and data from these months are used in the analysis. However, the months with an SPE event, as defined in the previous paragraph, were excluded. The RBE fluxes from MEPED are not reliable during SPEs (Rodger et al., 2010a), and SPE forcing would likely interfere with the RBE threshold detection. Indeed, exclusion of SPE months leads to stronger correlations between the RBE flux and odd hydrogen concentrations (not shown). For a full list of the months used in the analysis, refer to Table 1. As with SPEs, the RBE thresholds were found using linear fitting with square roots and the median and the standard deviation of odd hydrogen data (see Fig. 4b). For RBE events, threshold values with corresponding fluxconcentration correlation coefficients $\geq 0.25$ are accepted as reasonable.

As seen in Fig. 4a at $0.1-0.2$ protons $\mathrm{cm}^{-2} \mathrm{~s}^{-1} \mathrm{sr}^{-1}$, in some cases there is a large number of data points at low fluxes. To find out the impact on our analysis, we performed tests where we excluded these low-flux points. In general, correlations between flux data and $\mathrm{HO}_{x}$ concentrations become stronger, but thresholds increase due to larger standard deviation. These effects would, however, not change our conclusions.

\section{Results}

\subsection{Overall comparison between WACCM-D and MLS}

In general, WACCM-D and MLS compare reasonably well in the magnitude and spatiotemporal variability in $\mathrm{OH}$ and $\mathrm{HO}_{2}$. In both MLS and WACCM-D daytime concentration profiles, there is a maximum in the stratosphere and mesosphere, which reflects the production being dependent on atomic oxygen and Lyman-alpha radiation, respectively. Figure 5 shows a time series of monthly average daytime concentrations at magnetic latitude $70^{\circ} \mathrm{N}$, and these peaks and the seasonality of $\mathrm{HO}_{x}$ concentrations are clear in both MLS and WACCM-D. Overall, the greatest concentrations are seen in the summer months. Latitude-wise, the strongest concentrations are found at lower latitudes, with concentrations generally decreasing polewards (not shown). Lower latitudes also show the clearest stratospheric and mesospheric maxima and less seasonal variability than the polar regions.

WACCM-D shows a stronger stratospheric $\mathrm{OH}$ peak by $10 \%-20 \%$ and a weaker mesospheric $\mathrm{OH}$ peak by up to a factor of 2. In WACCM-D, the vertical transition between the $\mathrm{OH}$ summertime peaks is more continuous, while in MLS data there is a clear minimum between them around $0.1 \mathrm{hPa}$. EPP detection in the summer mesosphere is likely harder from MLS than WACCM-D because of larger background concentrations. In wintertime, both WACCM-D and MLS show lower OH values than in summer, particularly in the mesospheric altitudes, while the altitude distributions and concentrations are very similar. Similar observations can be made in daytime $\mathrm{HO}_{2}$ data as well (Fig. 5). Of the two maxima in the concentration profiles, the mesospheric one is stronger in MLS $\mathrm{HO}_{2}$ compared to WACCM-D, and MLS 


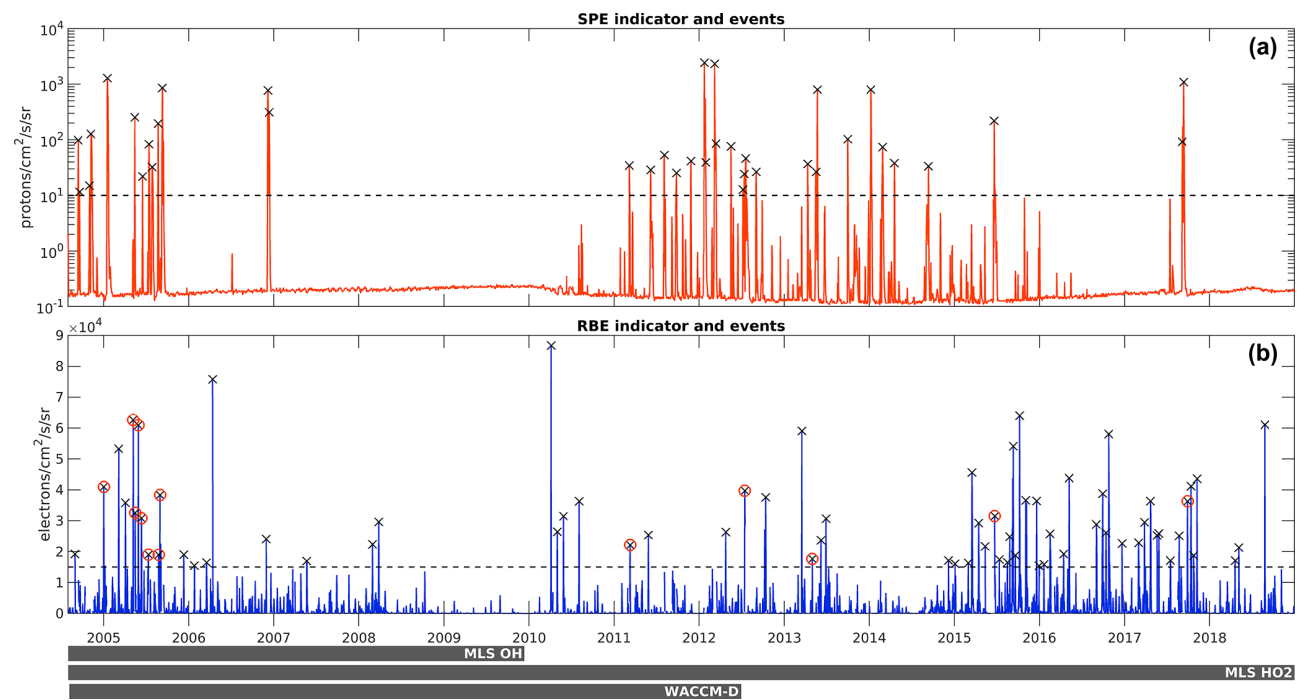

Figure 3. SPE indicator (a) and RBE indicator (b). Used precipitation limits for events are shown as dashed lines, and precipitation events are indicated by crosses. Encircled crosses mark RBE events with an SPE event in the same month. Availability of MLS OH and $\mathrm{HO}_{2}$ and WACCM-D data used in the analysis is also shown below the graphs.

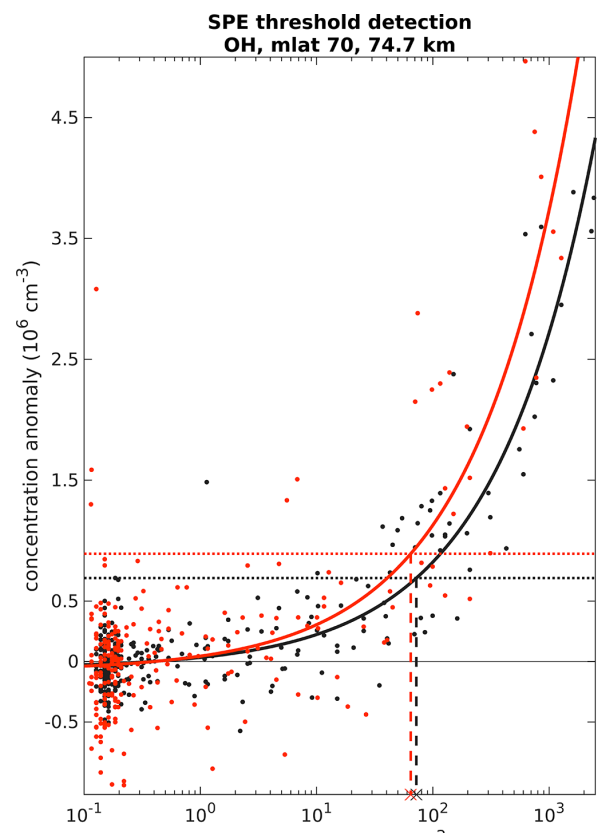

(a) SPE indicator (protons $/ \mathrm{cm}^{2} / \mathrm{s} / \mathrm{sr}$ )

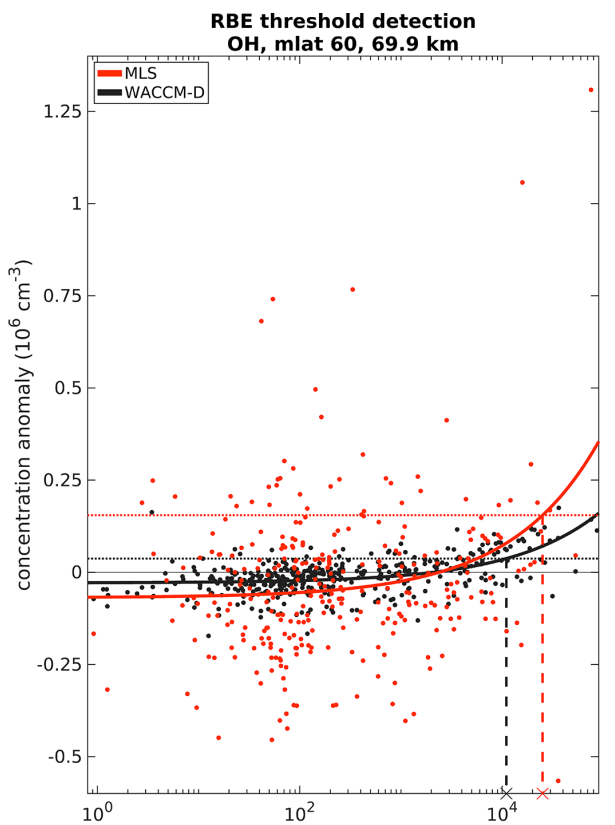

(b) RBE indicator (electrons $/ \mathrm{cm}^{2} / \mathrm{s} / \mathrm{sr}$ )

Figure 4. Precipitation threshold determination using nighttime $\mathrm{OH}$. (a) SPE indicator at magnetic latitude $70^{\circ} \mathrm{N}$ and $0.0215 \mathrm{hPa}(74.7 \mathrm{~km})$ and (b) RBE indicator at magnetic latitude $60^{\circ} \mathrm{N}$ and $0.0464 \mathrm{hPa}(69.9 \mathrm{~km})$. MLS data in red and WACCM-D in black. Daily indicator and $\mathrm{OH}$ concentration value pairs are shown as dots, and the linear fit is shown as a solid line. Used limits (median and SD; dotted horizontal lines) and detected threshold values (dashed vertical lines) are also shown. Note that the linear fitting was done using the square roots of the flux indicator values.

also has a clearer minimum between the two maxima at around $0.1 \mathrm{hPa}$. However, the noisiness of $\mathrm{MLS} \mathrm{HO}_{2}$ data is evident at lower atmospheric levels. Note that the $\mathrm{HO}_{2}$ data could be improved below the $1 \mathrm{hPa}$ level by using the daynight difference (Livesey et al., 2018), but this was not done in our analysis.
The nighttime concentrations show some similarities and differences as well, as seen in the time series of monthly average concentrations from magnetic latitude $60^{\circ} \mathrm{S}$ presented in Fig. 6. Overall, nightly concentrations are low in both MLS and WACCM-D. MLS $\mathrm{HO}_{2}$ is a clear exception at the lowest atmospheric levels, with much larger concentrations than in 
Table 1. Months included in the analysis, with dates (dd.mm.yyyy) of SPE and RBE flux peaks within each month (month/year) also given. For peaks within $5 \mathrm{~d}$ of each other, only the date of the strongest is included. Dates marked by ${ }^{\mathrm{a}}$ indicate dates in months where the event peak was in another month. RBE peak dates marked by ${ }^{b}$ are not included in the analysis, due to an SPE peak in the same month.

\begin{tabular}{|c|c|c|c|c|c|c|c|c|}
\hline Month & SPE peaks & RBE peaks & Month & SPE peaks & RBE peaks & Month & SPE peaks & RBE peaks \\
\hline 08/2004 & - & 31.08 .2004 & 08/2011 & 05.08.2011 & - & 07/2015 & - & 13.07 .2015 \\
\hline \multirow[t]{2}{*}{ 09/2004 } & 14.09 .2004 & - & 09/2011 & 26.09 .2011 & - & $08 / 2015$ & - & 17.08 .2015 \\
\hline & 20.09 .2004 & & $11 / 2011$ & 27.11.2011 & - & & & 27.08 .2015 \\
\hline \multirow[t]{2}{*}{$11 / 2004$} & 01.11 .2004 & - & $01 / 2012$ & 24.01 .2012 & - & 09/2015 & - & 11.09 .2015 \\
\hline & 08.11 .2004 & & & 30.01 .2012 & & & & 20.09 .2015 \\
\hline $01 / 2005$ & 17.01.2005 & $02.01 .2005^{\mathrm{b}}$ & 03/2012 & 08.03 .2012 & - & $10 / 2015$ & - & 08.10 .2015 \\
\hline 03/2005 & - & 07.03.2005 & & 14.03.2012 & & $11 / 2015$ & - & 04.11 .2015 \\
\hline 04/2005 & - & 05.04 .2005 & $04 / 2012$ & - & 25.04.2012 & $12 / 2015$ & - & 20.12 .2015 \\
\hline \multirow[t]{3}{*}{ 05/2005 } & 15.05 .2005 & $08.05 .2005^{\mathrm{b}}$ & $05 / 2012$ & 17.05 .2012 & - & & & 31.12 .2015 \\
\hline & & $16.05 .2005^{\mathrm{b}}$ & $07 / 2012$ & 07.07.2012 & $15.07 .2012^{\mathrm{b}}$ & $01 / 2016$ & - & 21.01.2016 \\
\hline & & $30.05 .2005^{\mathrm{b}}$ & & 13.07.2012 & & $02 / 2016$ & - & 16.02 .2016 \\
\hline 06/2005 & 17.06 .2005 & $12.06 .2005^{\mathrm{b}}$ & & 19.07.2012 & & $04 / 2016$ & - & 14.04 .2016 \\
\hline \multirow[t]{2}{*}{ 07/2005 } & 15.07.2005 & $12.07 .2005^{\mathrm{b}}$ & $09 / 2012$ & 02.09.2012 & - & $05 / 2016$ & - & 08.05.2016 \\
\hline & 29.07.2005 & & $10 / 2012$ & - & 13.10 .2012 & 09/2016 & - & 02.09 .2016 \\
\hline \multirow[t]{2}{*}{ 08/2005 } & 23.08.2005 & $25.08 .2005^{\mathrm{b}}$ & $03 / 2013$ & - & 17.03.2013 & & & 29.09 .2016 \\
\hline & & $31.08 .2005^{\mathrm{b}}$ & $04 / 2013$ & 11.04 .2013 & - & $10 / 2016$ & - & 13.10 .2016 \\
\hline 09/2005 & 10.09 .2005 & - & $05 / 2013$ & 17.05 .2013 & $01.05 .2013^{\mathrm{b}}$ & & & 25.10 .2016 \\
\hline $12 / 2005$ & - & 11.12 .2005 & & 23.05 .2013 & & $12 / 2016$ & - & 21.12 .2016 \\
\hline 01/2006 & - & 26.01 .2006 & $06 / 2013$ & - & 07.06 .2013 & 03/2017 & - & 02.03.2017 \\
\hline 03/2006 & - & 19.03.2006 & & & 29.06.2013 & & & 27.03.2017 \\
\hline $04 / 2006$ & - & $14.04 / 2006$ & 09/2013 & $30.09 .2013^{\mathrm{a}}$ & - & 04/2017 & - & 22.04 .2017 \\
\hline $11 / 2006$ & - & 30.11 .2006 & $10 / 2013$ & 01.10 .2013 & - & 05/2017 & - & 20.05 .2017 \\
\hline \multirow[t]{2}{*}{$12 / 2006$} & 07.12 .2006 & - & $01 / 2014$ & 08.01.2014 & - & & & 28.05 .2017 \\
\hline & 13.12 .2006 & & $02 / 2014$ & 27.02.2014 & - & 07/2017 & - & $17.07 / 2017$ \\
\hline 05/2007 & - & 23.05 .2007 & $03 / 2014$ & $01.03 .2014^{\mathrm{a}}$ & - & 08/2017 & - & 23.08 .2017 \\
\hline $02 / 2008$ & - & 29.02 .2008 & $04 / 2014$ & 19.04 .2014 & - & 09/2017 & 05.09 .2017 & $28.09 .2017^{b}$ \\
\hline 03/2008 & - & 27.03.2008 & 09/2014 & 12.09 .2014 & - & & 11.09 .2017 & \\
\hline 04/2010 & - & 06.04 .2010 & $12 / 2014$ & - & 07.12 .2014 & $10 / 2017$ & - & 13.10 .2017 \\
\hline \multirow[t]{2}{*}{ 05/2010 } & - & 02.05 .2010 & $01 / 2015$ & - & 04.01.2015 & & & 24.10 .2017 \\
\hline & & 29.05 .2010 & $03 / 2015$ & - & 02.03 .2015 & $11 / 2017$ & - & 08.11 .2017 \\
\hline 08/2010 & - & 04.08 .2010 & & & 18.03.2015 & $04 / 2018$ & - & 20.04 .2018 \\
\hline 03/2011 & 08.03.2011 & $11.03 .2011^{b}$ & $04 / 2015$ & - & 16.04 .2015 & $05 / 2018$ & - & 06.05 .2018 \\
\hline 05/2011 & - & 28.05 .2011 & $05 / 2015$ & - & 13.05 .2015 & 08/2018 & - & 26.08.2018 \\
\hline 06/2011 & 07.06.2011 & - & $06 / 2015$ & 21.06.2015 & $23.06 .2015^{\mathrm{b}}$ & & & \\
\hline
\end{tabular}

WACCM-D. Note, however, that the nighttime $\mathrm{HO}_{2}$ data are only valid from 1 to $0.0032 \mathrm{hPa}$, while from 10 to $1 \mathrm{hPa}$ the concentrations are close to zero and only used to correct the daytime observations. Thus, these high values are likely an artifact of the low signal-to-noise quality of the observations.

Both WACCM-D and MLS show the characteristic $\mathrm{OH}$ peak in the mesosphere, produced at night from reactions between atomic hydrogen and $\mathrm{O}_{2}$. The peak is approximately at the same pressure level of $0.01 \mathrm{hPa}$, but its magnitude is larger and the seasonal variability is weaker in WACCM-D. In summer, the peak occurs at a higher altitude and is stronger in both WACCM-D and MLS, although the altitude variation is slightly less obvious in MLS data. The MLS OH data also show oscillating minima and maxima in summertimes at 0.1-
$0.01 \mathrm{hPa}$, but these may be an artifact of the observations and are not seen in WACCM-D.

For $\mathrm{HO}_{2}$, WACCM-D shows an upper mesospheric peak with a clear seasonal cycle, coinciding with the $\mathrm{OH}$ peak. In addition, there is another clear peak at around $0.5 \mathrm{hPa}$, with a seasonal cycle that has a minimum in winter and clear maxima in spring and autumn. MLS $\mathrm{HO}_{2}$ data are noisy, and there are no clear patterns of seasonal variability.

Our WACCM-D/MLS $\mathrm{HO}_{2}$ comparison results are similar to those by Millán et al. (2015), although it should be noted that they presented the data in geographic coordinates. WACCM-D and MLS clearly produce similar structural patterns. Daytime peak in the mesosphere is stronger in MLS, with potential reasons including model deficiencies in chemistry, solar radiation, and meridional circulation from gravity 
Average monthly daytime concentrations, mlat 70
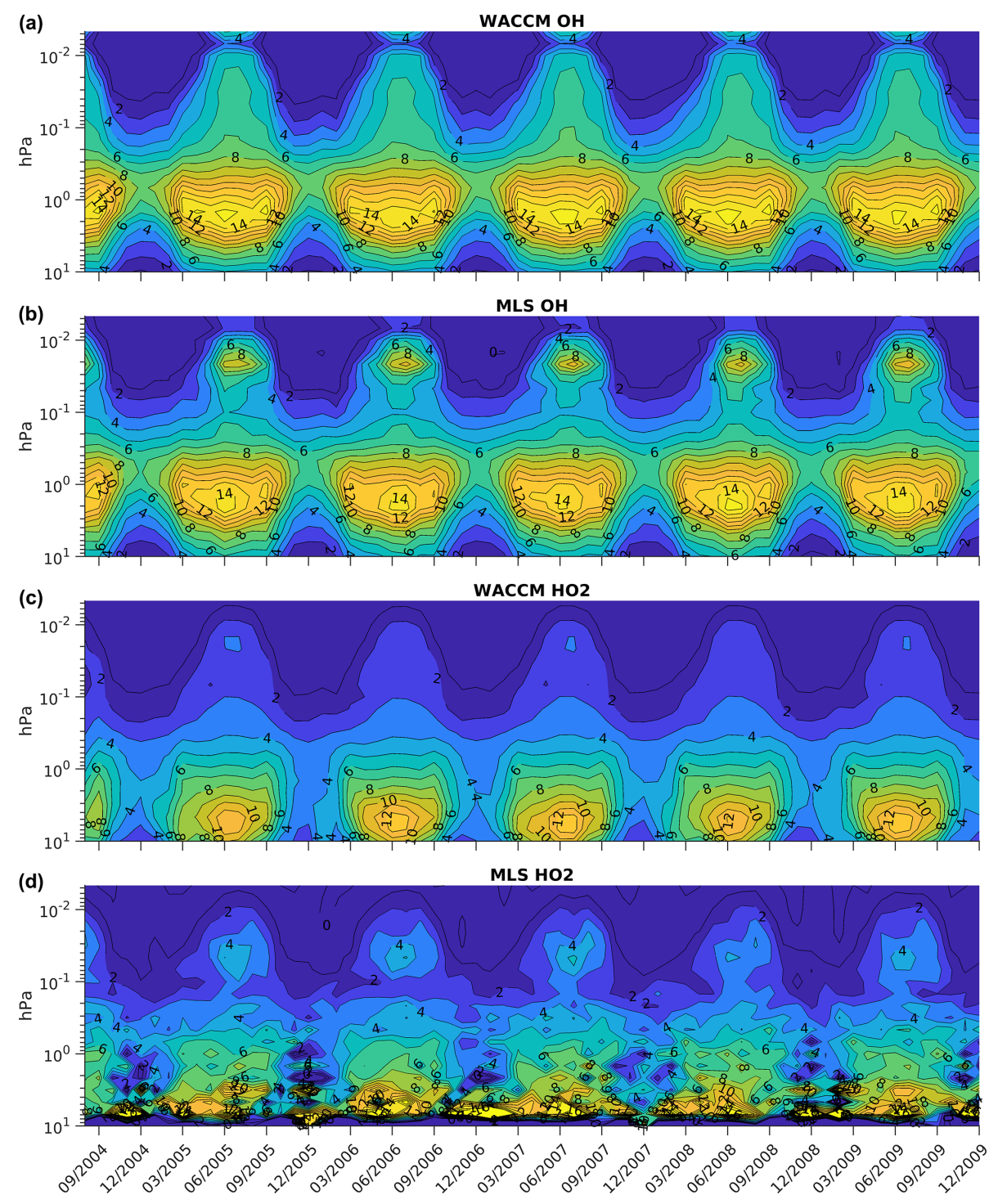

Figure 5. Monthly average daytime $\mathrm{OH}$ and $\mathrm{HO}_{2}$ concentrations on magnetic latitude $70^{\circ} \mathrm{N}$. From (a) to (d): WACCM-D OH; MLS OH; WACCM-D $\mathrm{HO}_{2} ; \mathrm{MLS} \mathrm{HO}_{2}$. Concentrations are in units $10^{6} \mathrm{~cm}^{-3}$.

waves (Millán et al., 2015). Nighttime differences are smaller than during daytime. Overall, the model and observations agree reasonably well, so EPP detection possibilities should be similar - at least in terms of the background level of $\mathrm{HO}_{x}$.

\subsection{SPE thresholds}

Figure 7a-c shows all detected nighttime SPE threshold values. As discussed in Sect. 3, correlations $\geq 0.35$ between the square root of the SPE indicator and $\mathrm{HO}_{x}$ data are taken as indication of reasonable thresholds. These correlations are shown in Fig. 7d-f. At higher latitudes in both hemispheres, i.e., at $60-80^{\circ}$, the correlations are distinctly high, while at other latitudes there is essentially no cor- relation. In the polar regions, the nightly threshold values are typically $50-130$ protons $\mathrm{cm}^{-2} \mathrm{~s}^{-1} \mathrm{sr}^{-1}$. At magnetic latitude $80^{\circ} \mathrm{S}$, the thresholds are lower than elsewhere, i.e., 35-80 protons $\mathrm{cm}^{-2} \mathrm{~s}^{-1} \mathrm{sr}^{-1}$, which would make this latitude band the best for SPE detection. The lower overall background concentration, especially in the $\mathrm{SH}$ due to the geomagnetic latitude distribution, makes detection easier, which leads to these lower thresholds. There are, however, larger variations at $80^{\circ} \mathrm{S}$ as well, due to smaller amount of data available, causing weaker correlations in the MLS observations. Overall, WACCM-D and MLS show similarly distributed threshold values. Comparing the thresholds from $\mathrm{OH}$, SPEs are detected lower into the atmosphere in WACCM-D than MLS data, i.e., from around $80 \mathrm{~km}$ down to 

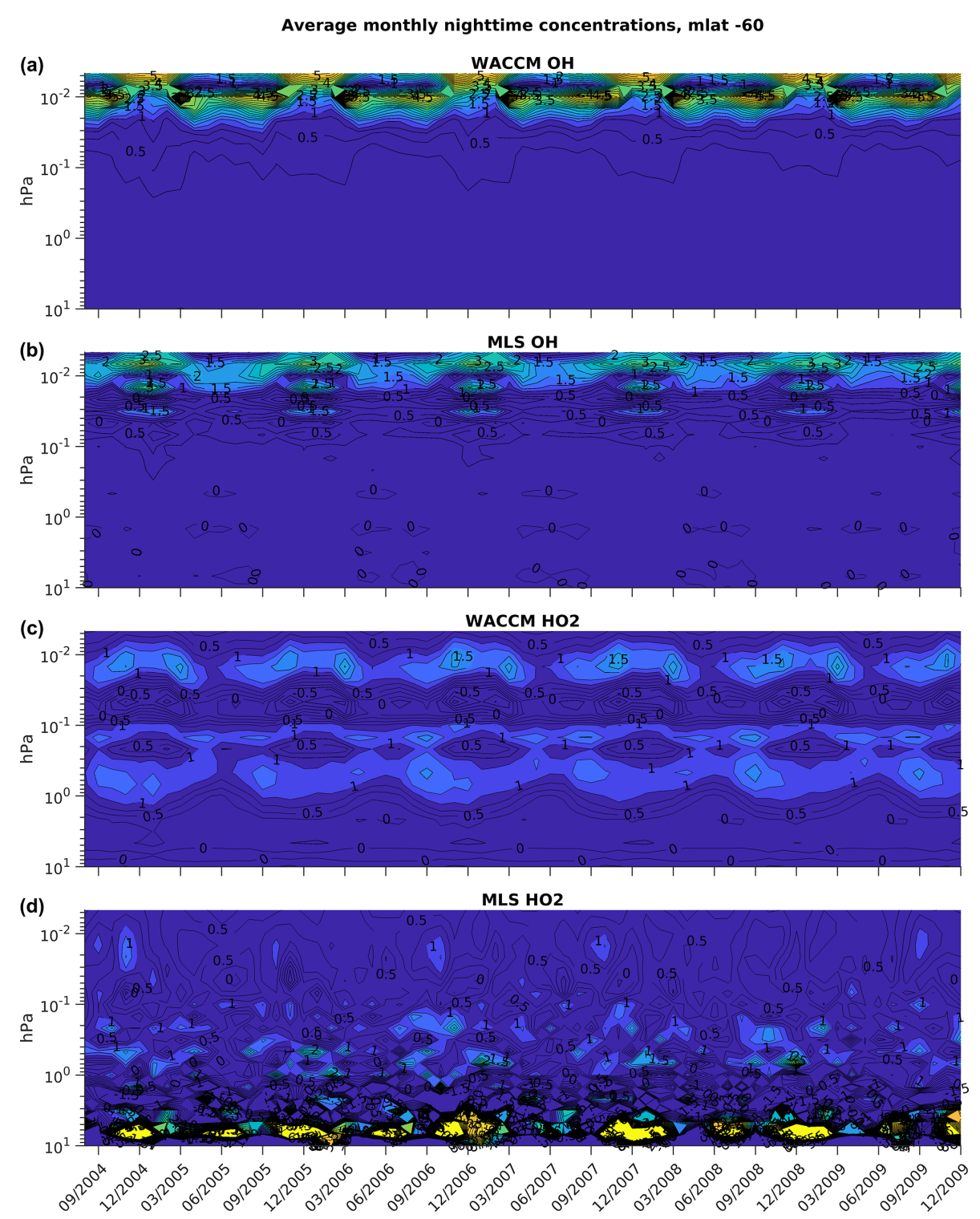

Figure 6. Monthly average nighttime $\mathrm{OH}$ and $\mathrm{HO}_{2}$ concentrations on magnetic latitude $60^{\circ} \mathrm{S}$. From (a) to (d): WACCM-D OH; MLS OH; WACCM-D $\mathrm{HO}_{2} ; \mathrm{MLS} \mathrm{HO}_{2}$. Concentrations are in units $10^{6} \mathrm{~cm}^{-3}$.

about 35 and $50 \mathrm{~km}$, respectively. This is seen in both hemispheres, in both thresholds and correlations, and can be explained by the MLS OH data becoming noisier in the stratosphere. In WACCM-D, the thresholds from $\mathrm{OH}$ and $\mathrm{HO}_{2}$ are very consistent, although correlations are weaker in $\mathrm{HO}_{2}$ in the Southern Hemisphere above $1 \mathrm{hPa}$.

Daytime SPE thresholds and correlations are shown in Fig. 8. Again, regions of high correlations are at high latitudes, $60-80^{\circ}$, as expected. Because the daytime background concentrations of $\mathrm{HO}_{x}$ are higher at most altitudes, the thresholds can be detected in a more restricted altitude range compared to nighttime. In WACCM-D, the detection can be done at $50-80 \mathrm{~km}$. Both the threshold values and the correlations are very similar for $\mathrm{HO}_{2}$ and $\mathrm{OH}$ data, even more so than at nighttime. For MLS OH, the correlations are overall lower than in WACCM-D, and there is a larger disparity between the $\mathrm{NH}$ and $\mathrm{SH}$. No thresholds are detected in the $\mathrm{SH}$, and in the $\mathrm{NH}$, a total of three grid points, all at latitude $80^{\circ} \mathrm{N}$, have high enough correlations to qualify as reasonable thresholds. The WACCM-D thresholds vary mostly from 85 to 130 protons $\mathrm{cm}^{-2} \mathrm{~s}^{-1} \mathrm{sr}^{-1}$, though there are many values up to 300 protons $\mathrm{cm}^{-2} \mathrm{~s}^{-1} \mathrm{sr}^{-1}$, while MLS OH thresholds range from 145 to 220 protons $\mathrm{cm}^{-2} \mathrm{~s}^{-1} \mathrm{sr}^{-1}$. Thus, the daytime threshold values are higher than for the nighttime, and there is larger range of values as well.

We do not include MLS $\mathrm{HO}_{2}$ in Figs. 7-8 because we could not detect thresholds due to the noisiness of the data. However, the correlations between MLS $\mathrm{HO}_{2}$ data and the 

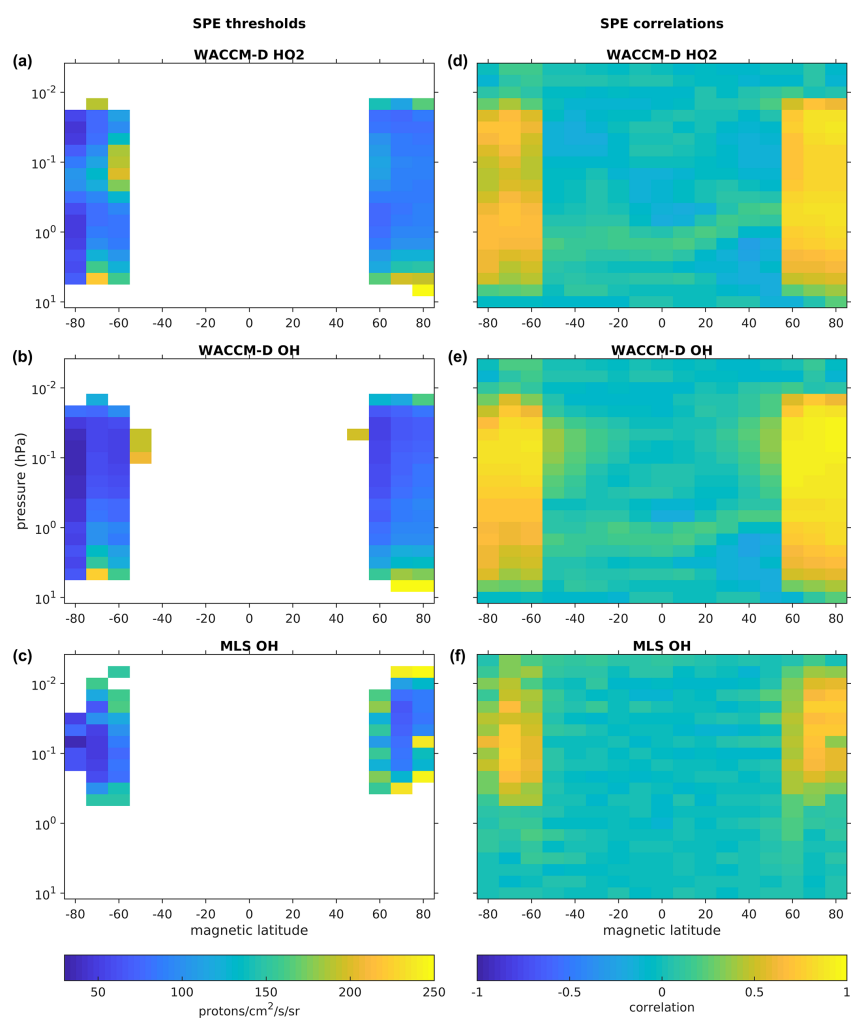

Figure 7. Nighttime SPE indicator thresholds (a-c) and corresponding correlations (d-f). WACCM-D $\mathrm{HO}_{2}$ (a, d), WACCM-D $\mathrm{OH}(\mathbf{b}, \mathbf{e})$, and MLS OH (c, f).

square root of the SPE indicator for both daytime and nighttime are shown in Fig. 9. The correlations are quite uniformly around zero, although there are some larger values seen in the NH high latitudes and altitudes. Nevertheless, no effect of proton precipitation is detectable in the MLS $\mathrm{HO}_{2}$ data. In the threshold detection analysis, the MLS averaging kernels were not applied to the WACCM-D data. However, we tested their impact and found that the averaging kernels lead to lower correlations overall and higher threshold values, especially at altitudes above $1 \mathrm{hPa}$. Thresholds could still be detected using WACCM-D data, especially in the NH (not shown).

In WACCM-D, the SPE forcing is applied uniformly at geomagnetic latitudes $>60^{\circ}$, and in $\mathrm{HO}_{x}$, the impact is detected at all the same latitudes. Observations also confirm that the same latitude extent is seen in MLS OH observations at night. Verronen et al. (2007) used MLS OH data to study the latitudinal extent of the proton forcing during the January $2005 \mathrm{SPE}$, comparing the results to a $1 \mathrm{D}$ atmospheric simulation. They found that the lowest geomagnetic latitude affected by the SPE varied between 57 and $64^{\circ}$ during the event. This agrees with our results, with SPE impact detected at latitude bins poleward of $55^{\circ}$ in the $\mathrm{NH}$ and $\mathrm{SH}$. On the other hand, Heino et al. (2019) compared the latitudinal extent of 62 SPEs using cosmic radio noise absorption from
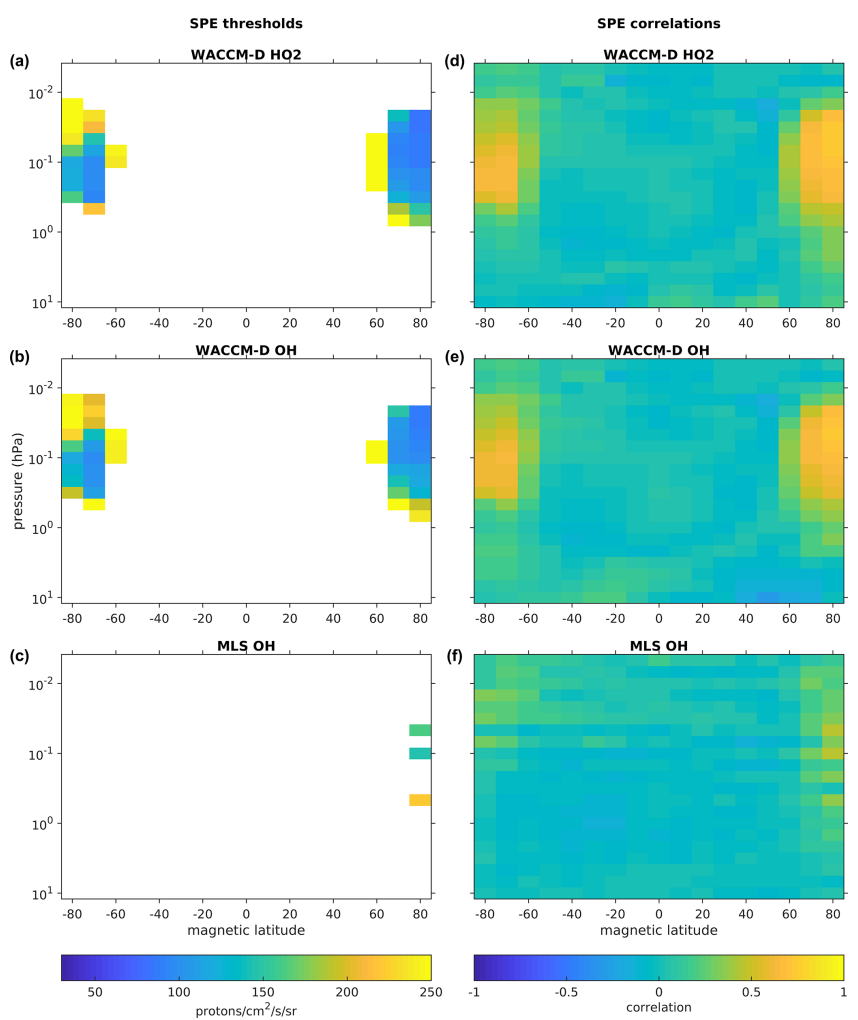

Figure 8. Daytime SPE indicator thresholds (a-c) and corresponding correlations (d-f). WACCM-D $\mathrm{HO}_{2}$ (a, d), WACCM-D $\mathrm{OH}(\mathbf{b}, \mathbf{e})$, and MLS OH $(\mathbf{c}, \mathbf{f})$.
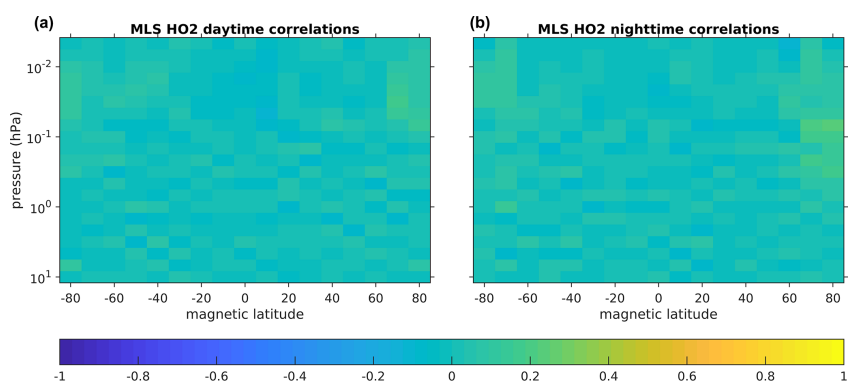

Figure 9. Correlations between SPE indicator and $\mathrm{MLS} \mathrm{HO}_{2}$ concentrations, showing (a) daytime and (b) nighttime. Due to the low correlations, no threshold values could be detected.

a chain of riometer (relative ionospheric opacity meter) observations to those calculated from WACCM-D ionospheric output. They concluded that WACCM-D tends to overestimate the SPE impact at geomagnetic latitudes $>66^{\circ}$. However, Heino et al. (2019) included a large number of smaller events which are expected to affect the highest latitudes only (e.g., Rodger et al., 2006). For the set of events considered by us, the SPE impact seems to cover all geomagnetic latitudes above $60^{\circ}$.

The SPE threshold fluxes from our $\mathrm{HO}_{x}$ analysis are of the order of 100 protons $\mathrm{cm}^{-2} \mathrm{~s}^{-1} \mathrm{sr}^{-1}$. Thus, our results are in 

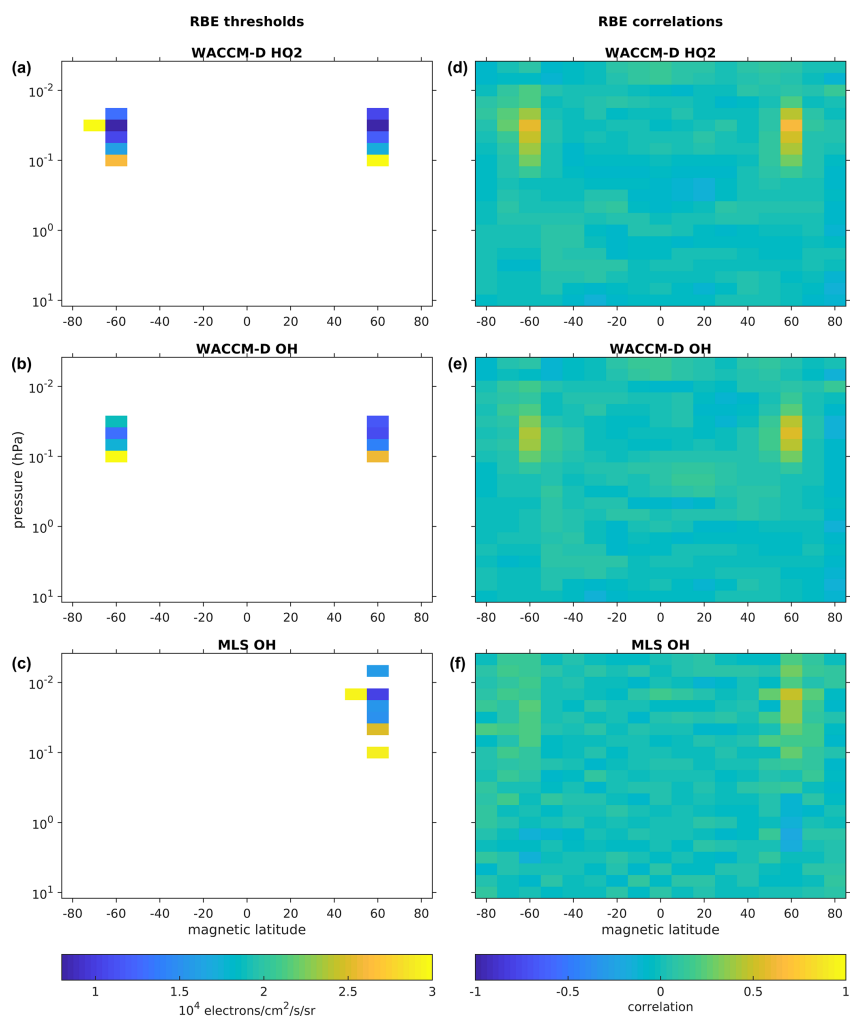

Figure 10. Nighttime RBE indicator thresholds (a-c) and corresponding correlations (d-f). WACCM-D $\mathrm{HO}_{2}$ (a, d), WACCM-D $\mathrm{OH}(\mathbf{b}, \mathbf{e})$, and MLS OH (c, f).

agreement with a recent simulation study of SPE-driven atmospheric impacts, which suggested little effect from SPEs with a smaller peak flux (Kalakoski et al., 2020). This detection limit means that, of the 130 SPEs recorded in 2004$2018,36(28 \%)$ have a peak daily flux large enough for $\mathrm{HO}_{x}$ based atmospheric detection.

\subsection{RBE detection}

The thresholds and correlations for nighttime RBE detection are shown in Fig. 10. In general, the $\mathrm{HO}_{x}$ reaction to radiation belt electron precipitation is more limited in altitude and latitude compared to proton precipitation, which can be expected from the spatial extent and energy range of the observed electron fluxes.

Overall, we detect RBE only at latitudes poleward of $60^{\circ}(\mathrm{NH}$ and $\mathrm{SH})$ and at altitudes from roughly 65 to $75 \mathrm{~km}$. In WACCM-D, the detection threshold is mostly $1.05-2.55 \times 10^{4}$ electrons $\mathrm{cm}^{-2} \mathrm{~s}^{-1} \mathrm{sr}^{-1}$, with lower values from WACCM-D when using the $\mathrm{HO}_{2}$ data. With MLS $\mathrm{OH}$ data, in the $\mathrm{NH}$ the detected $\mathrm{RBE}$ threshold values are similar to those with WACCM-D OH but with a slightly larger spread, i.e., $1.00-2.95 \times 10^{4}$ electrons $\mathrm{cm}^{-2} \mathrm{~s}^{-1} \mathrm{sr}^{-1}$, and cover a wider altitude range from 60 to $80 \mathrm{~km}$. MLS $\mathrm{OH}$ seems to show a wider latitude range for detection in
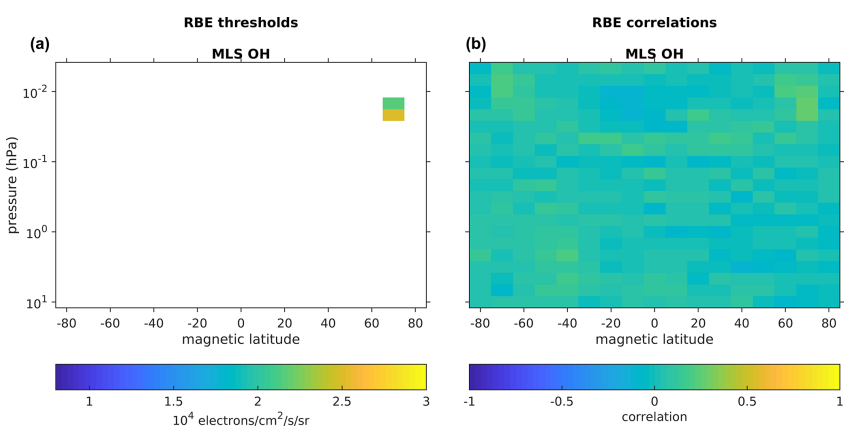

Figure 11. Daytime RBE indicator thresholds (a) and corresponding correlations (b) for MLS OH.

the correlations as well, extending over latitudes, $50-70^{\circ}$, although RBE can be detected only in one grid point outside $60^{\circ} \mathrm{N}$. A possible indication of this wider latitude range can also be seen in the SH in WACCM-D $\mathrm{HO}_{2}$, where a single threshold value can be detected at $70^{\circ} \mathrm{S}$. No thresholds can be found for MLS $\mathrm{HO}_{2}$ nighttime data, i.e., the situation is the same as for the SPE detection. There are no clear correlations between MLS $\mathrm{HO}_{2}$ and RBE indicator (not shown). In the daytime, all correlations between the $\mathrm{RBE}$ indicator and $\mathrm{HO}_{x}$ concentrations are low. The number of detected daytime RBE indicator threshold values is only two, both with MLS OH (Fig. 11). These thresholds are 2.16 and $2.50 \times 10^{4}$ electrons $\mathrm{cm}^{-2} \mathrm{~s}^{-1} \mathrm{sr}^{-1}$ at altitudes 0.0147 and $0.0215 \mathrm{hPa}$, respectively, both at magnetic latitude $70^{\circ} \mathrm{N}$.

In an attempt to improve some of the results, $5 \mathrm{~d}$ averaged data were also examined. A moving $5 \mathrm{~d}$ average was calculated from the $\mathrm{HO}_{x}$ data and analyzed, as above, with the SPE and RBE indicators. This was done to remove some of the noise, especially in the MLS $\mathrm{HO}_{2}$, but the results were not improved. The data smoothing effectively flattened out the daily concentration peaks caused by events, which generally led to slightly lower correlations with the SPE and RBE indicators. Thus, the daily values can be considered an optimal choice for EPP detection, taking into account that a typical SPE/RBE event duration is days.

Although RBE forcing in WACCM-D is applied at geomagnetic latitudes $40-72^{\circ}$, the detection in $\mathrm{HO}_{x}$ impact is only seen at $55-65^{\circ}$. Unlike the SPE forcing, RBE is not uniform over the latitude range but peaks at the heart of the outer radiation belt (van de Kamp et al., 2016). Thus, only this region can be used to detect the $\mathrm{HO}_{x}$ impact. In the MLS data, i.e., in the correlations shown in Fig. 10, the RBE extent in the $\mathrm{NH}$ seems to reach into neighboring bins outside $55-65^{\circ}$, although the correlation limit is not exceeded. This could indicate an underestimation in WACCM-D RBE forcing which is driven by the geomagnetic Ap index.

The RBE threshold fluxes are of the order of $10^{4}$ electrons $\mathrm{cm}^{-2} \mathrm{~s}^{-1} \mathrm{sr}^{-1}$, i.e., 100 times larger fluxes than for SPEs. This is consistent considering that $100 \mathrm{keV}$ elec- 
trons ionize about 100 times fewer molecules than $10 \mathrm{MeV}$ protons while penetrating to about the same atmospheric altitude. Considering the time period 2004-2018, there are 192 d, i.e., $3.9 \%$ of all days, which have RBE flux larger than the $10^{4}$ threshold. Note that our RBE thresholds are an order of magnitude larger than those given by Verronen et al. (2011). Analyzing four large RBE events, they estimated that it is not possible to detect the $\mathrm{HO}_{x}$ impact from electron forcing less than $10-30$ counts s$^{-1}$ as measured by MEPED, and this count rate corresponds to fluxes of $1-3 \times 10^{3}$ electrons $\mathrm{cm}^{-2} \mathrm{~s}^{-1} \mathrm{sr}^{-1}$ (Evans and Greer, 2004).

\section{Conclusions}

In this study, we have used atmospheric $\mathrm{HO}_{x}$ data as a detector of EPP impact in the mesosphere and stratosphere. In a sense, WACCM-D simulations have provided us with the theoretical thresholds for the detection, while MLS observations are the present reality that is affected also by the quality of the measurements.

Overall, SPE impacts can be well detected using average nighttime $\mathrm{OH}$ data from MLS. Based on the WACCM-D results, detection should be possible also at daytime and using $\mathrm{HO}_{2}$ data. In practice, however, the current MLS data do not have good enough signal-to-noise ratio to do this. RBE detection is possible as well but only at nighttime and for more limited altitude and latitude ranges. While the SPE impact can be seen rather uniformly poleward of $60^{\circ}$, the RBE impact is focused at $60^{\circ}$. As with SPEs, only MLS OH observations can be used for confident RBE detection on a day-byday basis.

Our analysis shows the extent of SPE atmospheric impacts, down to around 35 and $50 \mathrm{~km}$ in WACCM-D and MLS, respectively. The noise in MLS observations likely causes the difference in the altitude extent. Below $50 \mathrm{~km}$ altitudes, MLS $\mathrm{HO}_{x}$ cannot be reliably used to detect SPEs. Potentially, however, other species like $\mathrm{Cl}_{x}$ or $\mathrm{HNO}_{3}$ could provide better SPE detection capabilities in the stratosphere. For example, the simulations of SPE impacts by Kalakoski et al. (2020) showed enhancements in $\mathrm{Cl}_{x}$ and $\mathrm{HNO}_{3}$ between 1 and $0.01 \mathrm{hPa}$, lasting around a week, and longer-lasting (20$30 \mathrm{~d}$ ) effects below the $1 \mathrm{hPa}$ level in $\mathrm{HNO}_{3}$.

We find thresholds for EPP detection using the GOES $>10 \mathrm{MeV}$ proton fluxes and POES $100-300 \mathrm{keV}$ electron fluxes to be around $50-130$ protons $\mathrm{cm}^{-2} \mathrm{~s}^{-1} \mathrm{sr}^{-1}$ and 1.0 $2.5 \times 10^{4}$ electrons $\mathrm{cm}^{-2} \mathrm{~s}^{-1} \mathrm{sr}^{-1}$ at nighttime. These flux values have to be exceeded to cause a detectable $\mathrm{HO}_{x}$ impact. This limits the data usability to relatively large events. Note, however, that this does not mean that EPP with smaller fluxes is insignificant for the atmosphere. If applied for longer periods of time, EPP below the threshold limit can cause cumulative impacts on chemically long-lived species like $\mathrm{NO}_{x}$.

Although the MLS $\mathrm{HO}_{2}$ data were found to be too noisy for day-to-day EPP detection, they still have great potential for other purposes. For example, studies of solar cycle variability in the mesosphere could greatly benefit from the long time series. Also, it has been shown, e.g., by Jackman et al. (2014), that the MLS $\mathrm{HO}_{2}$ data are useful when the largest solar proton events are studied.

Code and data availability. MLS data are available from the NASA Goddard Space Flight Center Earth Sciences (GES) Data and Information Services Center (DISC; https://mls.jpl.nasa.gov/ data, last access: 17 December 2020, Livesey et al., 2018). All model data used are available on request from the corresponding author. CESM source code is distributed through a public subversion code repository (http://www.cesm.ucar.edu/models/cesm1.0/, last access: 17 December 2020, UCAR, 2020).

Author contributions. TH and PTV planned the research. LM prepared and provided the MLS $\mathrm{HO}_{2}$ offline data. MES carried out the WACCM-D simulations. TH analyzed the data, with all the coauthors participating in discussions. TH and PTV led the writing of the paper, with contributions from all the co-authors.

Competing interests. The authors declare that they have no conflict of interest.

Acknowledgements. The authors would like to thank the CHAMOS group (http://chamos.fmi.fi, last access: 17 December 2020) for the useful discussions.

Review statement. This paper was edited by Petr Pisoft and reviewed by two anonymous referees.

\section{References}

Andersson, M. E., Verronen, P. T., S. Wang, Rodger, C. J., Clilverd, M. A., and Carson, B.: Precipitating radiation belt electrons and enhancements of mesospheric hydroxyl during 2004-2009, J. Geophys. Res., 117, D09304, https://doi.org/10.1029/2011JD017246, 2012.

Andersson, M. E., Verronen, P. T., Rodger, C. J., Clilverd, M. A., and Seppälä, A.: Missing driver in the Sun-Earth connection from energetic electron precipitation impacts mesospheric ozone, Nat. Commun., 5, 5197, https://doi.org/10.1038/ncomms6197, 2014a.

Andersson, M. E., Verronen, P. T., Rodger, C. J., Clilverd, M. A., and Wang, S.: Longitudinal hotspots in the mesospheric $\mathrm{OH}$ variations due to energetic electron precipitation, Atmos. Chem. Phys., 14, 1095-1105, https://doi.org/10.5194/acp-141095-2014, 2014b.

Andersson, M. E., Verronen, P. T., Marsh, D. R., Päivärinta, S.-M., and Plane, J. M. C.: WACCM-D - Improved modeling of nitric acid and active chlorine during energetic parti- 
cle precipitation, J. Geophys. Res.-Atmos., 121, 10328-10341, https://doi.org/10.1002/2015JD024173, 2016.

Andersson, M. E., Verronen, P. T., Marsh, D. R., Seppälä, A., Päivärinta, S.-M., Rodger, C. J., Clilverd, M. A., Kalakoski, N., and van de Kamp, M.: Polar Ozone Response to Energetic Particle Precipitation Over Decadal Time Scales: The Role of Medium-Energy Electrons, J. Geophys. Res.-Atmos., 123, 607622, https://doi.org/10.1002/2017JD027605, 2018.

Baker, D. N., Erickson, P. J., Fennell, J. F., Foster, J. C., Jaynes, A. N., and Verronen, P. T.: Space weather effects in the Earth's radiation belts, Space Sci. Rev., 214, 17, https://doi.org/10.1007/s11214-017-0452-7, 2018.

Clilverd, M. A., Rodger, C. J., Danskin, D., Usanova, M. E., Raita, T., Ulich, T., and Spanswick, E. L.: Energetic Particle injection, acceleration, and loss during the geomagnetic disturbances which upset Galaxy 15, J. Geophys. Res., 117, A12213, https://doi.org/10.1029/2012JA018175, 2012.

Damiani, A., Storini, M., Rafanelli, C., and Diego, P.: The hydroxyl radical as an indicator of SEP fluxes in the highlatitude terrestrial atmosphere, Adv. Space Res., 46, 1225-1235, https://doi.org/10.1016/j.asr.2010.06.022, 2010a.

Damiani, A., Storini, M., Santee, M. L., and Wang, S.: Variability of the nighttime $\mathrm{OH}$ layer and mesospheric ozone at high latitudes during northern winter: influence of meteorology, Atmos. Chem. Phys., 10, 10291-10303, https://doi.org/10.5194/acp-10-102912010, 2010b.

Damiani, A., Funke, B., Santee, M. L., Cordero, R. R., and Watanabe, S.: Energetic particle precipitation: A major driver of the ozone budget in the Antarctic upper stratosphere, Geophys. Res. Lett., 43, 3554-3562, https://doi.org/10.1002/2016GL068279, 2016.

Evans, D. S. and Greer, M. S.: Polar Orbiting environmental satellite space environment monitor - 2 instrument descriptions and archive data documentation, NOAA Technical Memorandum version 1.4, Space Environment Laboratory, Colorado, 2004.

Funke, B., Baumgaertner, A., Calisto, M., Egorova, T., Jackman, C. H., Kieser, J., Krivolutsky, A., López-Puertas, M., Marsh, D. R., Reddmann, T., Rozanov, E., Salmi, S.-M., Sinnhuber, M., Stiller, G. P., Verronen, P. T., Versick, S., von Clarmann, T., Vyushkova, T. Y., Wieters, N., and Wissing, J. M.: Composition changes after the "Halloween" solar proton event: the High Energy Particle Precipitation in the Atmosphere (HEPPA) model versus MIPAS data intercomparison study, Atmos. Chem. Phys., 11, 90899139, https://doi.org/10.5194/acp-11-9089-2011, 2011.

Heino, E., Verronen, P. T., Kero, A., Kalakoski, N., and Partamies, N.: Cosmic noise absorption during solar proton events in WACCM-D and riometer observations, J. Geophys. Res.-Space, 124, 1361-1376, https://doi.org/10.1029/2018JA026192, 2019.

Jackman, C. H., McPeters, R. D., Labow, G. J., Fleming, E. L., Praderas, C. J., and Russel, J. M.: Northern hemisphere atmospheric effects due to the July 2000 solar proton events, Geophys. Res. Lett., 28, 2883-2886, 2001.

Jackman, C. H., Marsh, D. R., Vitt, F. M., Garcia, R. R., Randall, C. E., Fleming, E. L., and Frith, S. M.: Long-term middle atmospheric influence of very large solar proton events, J. Geophys. Res., 114, D11304, https://doi.org/10.1029/2008JD011415, 2009.

Jackman, C. H., Marsh, D. R., Vitt, F. M., Roble, R. G., Randall, C. E., Bernath, P. F., Funke, B., López-Puertas, M.,
Versick, S., Stiller, G. P., Tylka, A. J., and Fleming, E. L.: Northern Hemisphere atmospheric influence of the solar proton events and ground level enhancement in January 2005, Atmos. Chem. Phys., 11, 6153-6166, https://doi.org/10.5194/acp11-6153-2011, 2011.

Jackman, C. H., Randall, C. E., Harvey, V. L., Wang, S., Fleming, E. L., López-Puertas, M., Funke, B., and Bernath, P. F.: Middle atmospheric changes caused by the January and March 2012 solar proton events, Atmos. Chem. Phys., 14, 1025-1038, https://doi.org/10.5194/acp-14-1025-2014, 2014.

Kalakoski, N., Verronen, P. T., Seppälä, A., Szeląg, M. E., Kero, A., and Marsh, D. R.: Statistical response of middle atmosphere composition to solar proton events in WACCM-D simulations: the importance of lower ionospheric chemistry, Atmos. Chem. Phys., 20, 8923-8938, https://doi.org/10.5194/acp20-8923-2020, 2020.

Livesey, N. J., Read, W. G., Wagner, P. A., Froidevaux, L., Lambert, A., Manney, G. L., Valle, L. F. M., Pumphrey, H. C., Santee, M. L., Schwartz, M. J., Wang, S., Fuller, R. A., Jarnot, R. F., Knosp, B. W., Martinez, E., and Lay, R. R.: EOS MLS Version 4.2x Level 2 data quality and description document, JPL D-33509 Rev. D, Jet Propulsion Laboratory, 29 January 2018, Version 4.2x-3.1, 2018.

Marsh, D. R., Garcia, R. R., Kinnison, D. E., Boville, B. A., Sassi, F., Solomon, S. C., and Matthes, K.: Modeling the whole atmosphere response to solar cycle changes in radiative and geomagnetic forcing, J. Geophys. Res.-Atmos., 112, D23306, https://doi.org/10.1029/2006JD008306, 2007.

Marsh, D. R., Mills, M., Kinnison, D., Lamarque, J.-F., Calvo, N., and Polvani, L.: Climate change from 1850 to 2005 simulated in CESM1(WACCM), J. Climate, 26, 7372-7391, https://doi.org/10.1175/JCLI-D-12-00558.1, 2013.

Matthes, K., Funke, B., Andersson, M. E., Barnard, L., Beer, J., Charbonneau, P., Clilverd, M. A., Dudok de Wit, T., Haberreiter, M., Hendry, A., Jackman, C. H., Kretzschmar, M., Kruschke, T., Kunze, M., Langematz, U., Marsh, D. R., Maycock, A. C., Misios, S., Rodger, C. J., Scaife, A. A., Seppälä, A., Shangguan, M., Sinnhuber, M., Tourpali, K., Usoskin, I., van de Kamp, M., Verronen, P. T., and Versick, S.: Solar forcing for CMIP6 (v3.2), Geosci. Model Dev., 10, 2247-2302, https://doi.org/10.5194/gmd-10-2247-2017, 2017.

Millán, L., Wang, S., Livesey, N., Kinnison, D., Sagawa, H., and Kasai, Y.: Stratospheric and mesospheric $\mathrm{HO}_{2}$ observations from the Aura Microwave Limb Sounder, Atmos. Chem. Phys., 15, 2889-2902, https://doi.org/10.5194/acp-15-2889-2015, 2015.

Pickett, H. M., Drouin, B. J., Canty, T., Kovalenko, L. J., Salawitch, R. J., Livesey, N. J., Read, W. G., Waters, J. W., Jucks, K. W., and Traub, W. A.: Validation of Aura MLS $\mathrm{HO}_{x}$ measurements with remote-sensing balloon instruments, Geophys. Res. Lett., 33, L01808, https://doi.org/10.1029/2005GL024048, 2006a.

Pickett, H. M., Read, W. G., Lee, K. K., and Yung, Y. L.: Observation of night $\mathrm{OH}$ in the mesosphere, Geophys. Res. Lett., 33, L19808, https://doi.org/10.1029/2006GL026910, 2006b.

Pickett, H. M., Drouin, B. J., Canty, T., Salawitch, R. J., Fuller, R. A., Perun, V. S., Livesey, N. J., Waters, J. W., Stachnik, R. A., Sander, S. P., Traub, W. A., Jucks, K. W., and Minschwaner, K.: Validation of Aura Microwave Limb Sounder $\mathrm{OH}$ and $\mathrm{HO}_{2}$ measurements, J. Geophys. Res., 113, D16S30, https://doi.org/10.1029/2007JD008775, 2008. 
Randall, C. E., Harvey, V. L., Holt, L. A., Marsh, D. R., Kinnison, D., Funke, B., and Bernath, P. F.: Simulation of energetic particle precipitation effects during the 20032004 Arctic winter, J. Geophys. Res.-Space, 120, 5035-5048, https://doi.org/10.1002/2015JA021196, 2015.

Rienecker, M. M., Suarez, M. J., Gelaro, R., Todling, R., Bacmeister, J., Liu, E., Bosilovich, M. G., Schubert, S. D., Takacs, L., Kim, G.-K., Bloom, S., Chen, J., Collins, D., Conaty, A., da Silva, A., Gu, W., Joiner, J., Koster, R. D., Lucchesi, R., Molod, A., Owens, T., Pawson, S., Pegion, P., Redder, C. R., Reichle, R., Robertson, F. R., Ruddick, A. G., Sienkiewicz, M., and Woollen, J.: MERRA: NASA's Modern-Era Retrospective Analysis for Research and Applications, J. Climate, 24, 3624-3648, https://doi.org/10.1175/JCLI-D-11-00015.1, 2011.

Rodger, C. J., Clilverd, M. A., Verronen, P. T., Ulich, T., Jarvis, M. J., and Turunen, E.: Dynamic geomagnetic rigidity cutoff variations during a solar proton event, J. Geophys. Res., 111, A04222, https://doi.org/10.1029/2005JA011395, 2006.

Rodger, C. J., Clilverd, M. A., Green, J. C., and Lam, M. M.: Use of POES SEM-2 observations to examine radiation belt dynamics and energetic electron precipitation into the atmosphere, J. Geophys. Res.-Space, 115, A04202, https://doi.org/10.1029/2008JA014023, 2010a.

Seppälä, A., Matthes, K., Randall, C. E., and Mironova, I. A.: What is the solar influence on climate? Overview of activities during CAWSES-II, Prog. Earth Planet. Sci., 1, 24, https://doi.org/10.1186/s40645-014-0024-3, 2014.

Shepherd, S. G.: Altitude-adjusted corrected geomagnetic coordinates: Definition and functional approximations, J. Geophys. Res.-Space, 119, 7501-7521, https://doi.org/10.1002/2014JA020264, 2014.

Sinnhuber, M., Nieder, H., and Wieters, N.: Energetic particle precipitation and the chemistry of the mesosphere/lower thermosphere, Surv. Geophys., 33, 1281-1334, https://doi.org/10.1007/s10712-012-9201-3, 2012.

Turunen, E., Verronen, P. T., Seppälä, A., Rodger, C. J., Clilverd, M. A., Tamminen, J., Enell, C.-F., and Ulich, T.: Impact of different precipitation energies on $\mathrm{NO}_{x}$ generation during geomagnetic storms, J. Atmos. Sol.-Terr. Phys., 71, 1176-1189, https://doi.org/10.1016/j.jastp.2008.07.005, 2009.

UCAR: CESM1.0 PUBLIC RELEASE, available at: http://www. cesm.ucar.edu/models/cesm1.0/, last access: 17 December 2020. van de Kamp, M., Seppälä, A., Clilverd, M. A., Rodger, C. J., Verronen, P. T., and Whittaker, I. C.: A model providing longterm datasets of energetic electron precipitation during geomagnetic storms, J. Geophys. Res.-Atmos., 121, 12520-12540, https://doi.org/10.1002/2015JD024212, 2016.

van de Kamp, M., Rodger, C. J., Seppälä, A., Clilverd, M. A., and Verronen, P. T.: An updated model providing longterm datasets of energetic electron precipitation, including zonal dependence, J. Geophys. Res.-Atmos., 123, 9891-9915, https://doi.org/10.1029/2017JD028253, 2018.
Verronen, P. T., Seppälä, A., Kyrölä, E., Tamminen, J., Pickett, H. M., and Turunen, E.: Production of odd hydrogen in the mesosphere during the January 2005 solar proton event, Geophys. Res. Lett., 33, L24811, https://doi.org/10.1029/2006GL028115, 2006.

Verronen, P. T., Rodger, C. J., Clilverd, M. A., Pickett, H. M., and Turunen, E.: Latitudinal extent of the January 2005 solar proton event in the Northern Hemisphere from satellite observations of hydroxyl, Ann. Geophys., 25, 2203-2215, https://doi.org/10.5194/angeo-25-2203-2007, 2007.

Verronen, P. T., Rodger, C. J., Clilverd, M. A., and Wang, S.: First evidence of mesospheric hydroxyl response to electron precipitation from the radiation belts, J. Geophys. Res., 116, D07307, https://doi.org/10.1029/2010JD014965, 2011.

Verronen, P. T., Andersson, M. E., Rodger, C. J., Clilverd, M. A., Wang, S., and Turunen, E.: Comparison of modeled and observed effects of radiation belt electron precipitation on mesospheric hydroxyl and ozone, J. Geophys. Res., 118, 1141911428, https://doi.org/10.1002/jgrd.50845, 2013.

Verronen, P. T., Andersson, M. E., Kero, A., Enell, C.-F., Wissing, J. M., Talaat, E. R., Kauristie, K., Palmroth, M., Sarris, T. E., and Armandillo, E.: Contribution of proton and electron precipitation to the observed electron concentration in OctoberNovember 2003 and September 2005, Ann. Geophys., 33, 381394, https://doi.org/10.5194/angeo-33-381-2015, 2015.

Verronen, P. T., Andersson, M. E., Marsh, D. R., Kovács, T., and Plane, J. M. C.: WACCM-D - Whole Atmosphere Community Climate Model with D-region ion chemistry, J. Adv. Model. Earth Syst., 8, 954-975, https://doi.org/10.1002/2015MS000592, 2016.

Wang, S., Pickett, H. M., Pongetti, T. J., Cheung, R., Yung, Y. L., Li, C. S. Q., Canty, T., Salawitch, R. J., Jucks, K. W., Drouin, B., and Sander, S. P.: Validation of Aura Microwave Limb Sounder OH measurements with Fourier Transform UltraViolet Spectrometer total $\mathrm{OH}$ column measurements at Table Mountain, California, J. Geophys. Res.-Atmos., 113, D22301, https://doi.org/10.1029/2008JD009883, 2008.

Waters, J. W., Froidevaux, L., Harwood, R. S., Jarnot, R. F., Pickett, H. M., Read, W. G., Siegel, P. H., Cofield, R. E., Filipiak, M. J., Flower, D. A., Holden, J. R., Lau, G. K., Livesey, N. J., Manney, G. L., Pumphrey, H. C., Santee, M. L., Wu, D. L., Cuddy, D. T., Lay, R. R., Loo, M. S., Perun, V. S., Schwartz, M. J., Stek, P. C., Thurstans, R. P., Boyles, M. A., Chandra, K. M., Chavez, M. C., Chen, G.-S., Chudasama, B. V., Dodge, R., Fuller, R. A., Girard, M. A., Jiang, J. H., Jiang, Y., Knosp, B. W., Labelle, R. C., Lam, J. C., Lee, A. K., Miller, D., Oswald, J. E., Patel, N. C., Pukala, D. M., Quintero, O., Scaff, D. M., Vansnyder, W., Tope, M. C., Wagner, P. A., and Walch, M. J.: The Earth Observing System Microwave Limb Sounder (EOS MLS) on the Aura satellite, IEEE T. Geosci. Remote Sens., 44, 1075-1092, https://doi.org/10.1109/TGRS.2006.873771, 2006.

Zou, Z., Xue, X., Shen, C., Yi, W., Wu, J., Chen, T., and Dou, X.: Response of Mesospheric $\mathrm{HO}_{2}$ and $\mathrm{O}_{3}$ to Large Solar Proton Events, J. Geophys. Res.-Space, 123, 5738-5746, https://doi.org/10.1029/2018JA025481, 2018. 